\title{
Can a cyclooxygenase inhibitor be an option for treatment of ovarian hyperstimulation syndrome?
}

This article was published in the following Dove Medical Press journal:

Drug Design, Development and Therapy

\section{Hasan Çilgin}

Medicine Faculty, Obstetrics and Gynecology Department, Kafkas University, Kars, Turkey
Correspondence: Hasan Çilgin Medicine Faculty, Obstetrics and Gynecology Department, Kafkas University, Turan Çelik Cad, Kars 36100, Turkey

Tel +90 5332279980

Email munzurluhasan@yahoo.com
Purpose: This study aimed to investigate the role of a cyclooxygenase inhibitor in ovarian hyperstimulation syndrome (OHSS) treatment and compare it with cabergoline.

Materials and methods: A total of 32 immature female Wistar albino rats were randomly divided into four groups, with each group consisting of eight rats. The first group received only saline for 6 consecutive days, and the remaining 24 rats were given 10 IU of recombinant follicle stimulating hormone subcutaneously on 5 consecutive days. On day 6, 30 IU of human chorionic gonadotropin was administered for OHSS induction. After the development of OHSS, while the second group had no further intervention, the third and fourth groups were given cabergoline and celecoxib daily for 6 days, respectively. Besides weight and hematocrit values, vascular endothelial growth factor (VEGF), IL-2, and endothelin-1 (ET-1) levels were evaluated. Results: Initially, no significant differences were observed between the groups with respect to the evaluated parameters. Although there were no differences between the weight and hematocrit values at the end of treatment $(P=0.158, P=0.674)$, the difference between group 1 and the other groups was statistically significant after OHSS was established ( $P=0.001, P=0.004)$. Comparison of the groups in terms of VEGF, ET-1, and IL-2 levels revealed that the difference between group 1 and the other groups was significant after OHSS was formed $(P=0.012, P=0.018$, $P=0.015)$. After treatment, however, a significant difference was observed only between group 2 and the other groups $(P=0.001, P=0.002, P=0.038)$.

Conclusion: According to these results, celecoxib significantly decreased VEGF, IL-2, and ET-1 levels as much as cabergoline and could reduce the extent of OHSS development.

Keywords: cabergoline, celecoxib, cyclooxygenase type 2, endothelin-1, IL-2, ovarian hyperstimulation syndrome

\section{Introduction}

Ovarian hyperstimulation syndrome (OHSS) is an iatrogenic complication that occurs as a result of treatments including ovulation induction and assisted reproductive technology (ART). It is characterized by cystic dilatation of the ovaries and a rapid shift of fluid from the intravascular compartment into the third cavity. ${ }^{1}$ The trigger factor for this syndrome, independent of exogenous or endogenous exposure, is human chorionic gonadotropin (hCG). It is thought that hCG exerts this effect on OHSS through upregulation of an angiogenic molecule, vascular endothelial growth factor (VEGF). ${ }^{2}$ OHSS affects $12 \%-25 \%$ of in vitro fertilization cycles. In addition, in ART cycles, severe form of this syndrome can be observed in $0.5 \%-5 \%$ of the cases. Not only because it is a life-threatening syndrome, but also because its pathophysiology is difficult to understand, researchers have been impelled to begin working on OHSS extensively. ${ }^{3}$ After ovulation induction, vascular permeability is thought to be affected by many factors, such as cytokines, including ILs, renin angiotensin system-associated 
factors, tumor necrosis factor- $\alpha$, VEGF, and endothelin-1 (ET-1). ${ }^{4}$ Experimental animal models have demonstrated that the main reason for increased vascular permeability after in vivo use of gonadotropins was the addition of hCG. In contrast, it has been shown that blocking the VEGF receptor with a dopamine agonist or adding specific VEGF inhibitors can normalize vascular permeability. 5,6 Administration of hCG significantly increases VEGF and VEGF receptor 2, resulting in increased vascular permeability, which is the main underlying pathophysiology of this clinical condition. ${ }^{7}$ When cabergoline is administered within 9 days following hCG administration, it reduces the initiation of early OHSS without affecting luteal angiogenesis by partially inhibiting the VEGF receptor 2 phosphorylation levels and associated vascular permeability. ${ }^{8}$

T-helper cells produce and secrete IL-2, which acts as a central regulator or mediator of the immune response. Many toxic side effects have been observed including "vascular leak syndrome", which mimics OHSS when IL-2 is administered to humans. To further support this concept, IL-2 levels were measured during oocyte collection in follicular fluids of patients who subsequently developed OHSS. When patients with severe OHSS were compared with controls, by hCG concentration, a dose-response modulation of IL-2 production in the granulosa cell microenvironment and higher IL-2 mRNA levels in peripheral blood mononuclear cells were seen. ${ }^{9}$

Detection of ET-1 at high concentrations in follicular fluid samples of patients receiving ovulation induction and a positive correlation between ET-1 and follicle stimulating hormone (FSH) in follicular fluid suggest that ET-1 plays a role in the pathogenesis of OHSS and ovarian function. ${ }^{10}$

In tumor models, cyclooxygenase $2(\mathrm{COX}-2)$ inhibitors have been shown to inhibit angiogenesis. Recently, the selective COX-2 inhibitor NS389 was shown to inhibit autologous endometrial graft growth by inhibiting angiogenesis in a Syrian hamster skinfold chamber model. ${ }^{11}$ When cells were exposed to daily systemic usage of COX-2 inhibitors, VEGF expression was inhibited, and as a result of proliferation and apoptosis activation, vascular density of the lesions decreased. ${ }^{12}$

A large randomized controlled trial conducted with nonsteroidal anti-inflammatory agents showed that the use of low-dose aspirin in the high-risk group reduced the incidence of OHSS without affecting pregnancy outcomes. ${ }^{13}$ Meloxicam was also able to reduce ovarian weight and VEGF expression associated with OHSS in an animal model. ${ }^{14}$
The upregulation of COX-2 inhibition reduced fertility due to ovulation suppression (luteinized unruptured follicle syndrome), in which follicles failed to develop, but the selective COX-2 inhibitor celecoxib showed no negative effect on oestrous cycles in rats. ${ }^{15}$

These observations made me consider that celecoxib may have a preventative and therapeutic role in OHSS and compelled me to investigate the effect of celecoxib on VEGF, ET-1, and IL-2 in an experimentally induced rat model.

\section{Materials and methods Study design and rat grouping}

Following an acclimation period, thirty-two, 24-day-old rats were randomly divided into four groups (each consisting of eight animals). The first group (control group) received $0.2 \mathrm{~mL}$ of subcutaneous saline for 6 consecutive days (days 25-30) and no further intervention. Subcutaneous injections of 10 IU recombinant FSH (Gonal-f; Darmstadt, Germany) were administered to the remaining 24 rats on 5 consecutive days (on a daily basis from day 25 to day 29). Then, on day 6, 30 IU of hCG (Pregnyl; N.V. Organon, Schiphol-Rijk, the Netherlands) was administered for induction of ovarian hyperstimulation. After OHSS induction (on a daily basis till day 30 ), the rats were randomly divided into three equal groups, resulting in a total of four groups. Group 2 (OHSS group) received no intervention after hCG was administered and OHSS was established. After OHSS induction, group 3 (cabergoline group) received $100 \mathrm{mg} / \mathrm{kg}$ of cabergoline (Dostinex; Pfizer, New York, NY, USA) orally for 6 days, and group 4 (celecoxib group) received $25 \mathrm{mg} / \mathrm{kg}$ of celecoxib (Celebrex; Pfizer) orally for 6 days. All groups were evaluated in terms of weight, hematocrit, VEGF, ET-1, and IL-2 levels on the initial day of the study (day 0 ), on day 6 (pretreatment), and on day 12 (after treatment following decapitation on day 36). Decapitation was performed under general anesthesia following administration of intraperitoneal ketamine (75 mg/kg, Ketalar $500 \mathrm{mg}$ injectable vial; Pfizer) and xylazine (10 mg/kg, Xylased $100 \mathrm{mg}$ ampule; Bioveta, Ivanovice na Hank, Czechoslovakia). All hormones were administered subcutaneously. Increased weight and hematocrit values were the criteria for successful establishment of OHSS as previously described by Ohba et al. ${ }^{16}$

Throughout the study, the rats were kept in groups of eight per cage and exposed to 12 hours of artificial light and dark cycles. Rats were fed with standard pellets and tap water. Age-appropriate rats were used for the study to eliminate or reduce age-related differences. 


\section{Characteristics of rats}

This study was conducted on thirty-two, 24-day-old immature female Wistar albino rats, weighing 44-64 g. Prior to the start of the study, the rats were given 12 days of acclimation.

\section{Laboratory operations}

After decapitation, about $3 \mathrm{~mL}$ of blood was taken from each rat. For the separation of sera, blood samples were centrifuged at 2,500 rpm for 4 minutes and were kept at $-20^{\circ} \mathrm{C}$ until assaying for all parameters. VEGF was evaluated with a rat VEGF ELISA kit (ELR-VEGF-1; RayBiotech, Norcross, GA, USA), ET-1 was measured using an endothelin-1 E/Kit (EK-023-01; Phoenix Pharmaceuticals, Mountain View, CA, USA), and IL-2 (EK-042-01; Biored, Istanbul, Turkey) was analyzed using the immunoassay method.

\section{Main outcome measures}

As the main outcome criteria, weight (g), hematocrit (\%), and serum levels of VEGF ( $\mathrm{pg} / \mathrm{mL}), \mathrm{IL}-2(\mathrm{pg} / \mathrm{mL})$, and ET-1 $(\mathrm{ng} / \mathrm{mL})$ were measured.

\section{Ethical approval}

The Local Animal Ethical Committee of Kafkas University approved the study (on 24/11/2016, session no: 2016/119, decision no: 11). All interventions were conducted according to the National Institutes of Health Guide for the Care and Use of Laboratory Animals.

After ethical approval, the study was conducted at the Laboratory Center for Experimental Studies of Kafkas University.

\section{Statistical analyses}

For the analysis of data, SPSS version 21.0 was used (IBM Corporation, Armonk, NY, USA). The results were expressed as mean $\pm \mathrm{SD}$. Differences between the groups were assessed by one-way ANOVA when appropriate followed by the Tukey's test or the Student's $t$-test. $P$-values $\leq 0.05$ were considered statistically significant.

\section{Results}

The results showed that OHSS, which I intended to create experimentally, was successfully induced in the three intervention groups. Initially, there was no statistically significant difference in weight, hematocrit, VEGF, IL-2, and ET-1 levels between the groups (Figure 1). Although there was no difference between the weight of rats at the end of treatment $(P=0.158)$, except for the difference between group 1 and the other groups after OHSS was established, binary comparative statistics among the other groups were not statistically significant $(P=0.001)$. When the rats were compared in terms of hematocrit values, although the difference was not statistically significant at baseline, the value was statistically significant at day 6 between group 1 and the other groups only ( $P=0.004)$. The difference between hematocrit values at day 12 was again not statistically significant $(P=0.674)$. When the groups were compared in terms of VEGF, the difference between group 1 and the other groups was statistically significant after OHSS was induced $(P=0.012)$. After treatment, however, a significant difference was observed between group 2 and the other groups only ( $P=0.001)$. The same was true for ET-1, which means that when ET-1 levels were compared after OHSS formation $(P=0.018)$, only the difference between group 1 and the other groups was statistically significant. There was a statistically significant difference between group 2 and the other groups following treatment $(P=0.002)$, and no statistically significant difference was found in other binary comparisons. As for IL-2, there was a statistically significant difference between group 1 and the other groups on day $6(P=0.015)$. On the other hand, following treatment a significant difference was observed in binary comparisons between group 2 and the other groups only $(P=0.038)$ (Table 1$)$.

\section{Discussion}

The cause of OHSS, which is known to occur after fertility treatments, has not been precisely established. This has led to the investigation of possible mechanisms. In this context, the author aimed to investigate the role of VEGF, ET-1, and IL-2 in the formation of OHSS, to examine how these parameters change with celecoxib treatment, and to compare the effects of celecoxib and cabergoline on these parameters in a hyperstimulation rat model. The selected drugs are directed at cascades that are involved in the mechanisms of OHSS and are easily administered, safe, stable, and have previously been used in humans for a variety of reasons.

In this study, all three intervention groups were characterized by increased weight, and hematocrit, VEGF, IL-2, and ET-1 values compared to the control group on day 6 . In addition, it seemed that increased weight and hematocrit value in the OHSS-induced rat groups might have resulted from the effects of these markers and demonstrated experimentally successful creation of OHSS. Although there was no significant difference between weight and hematocrit values between the groups after treatment, the differences 

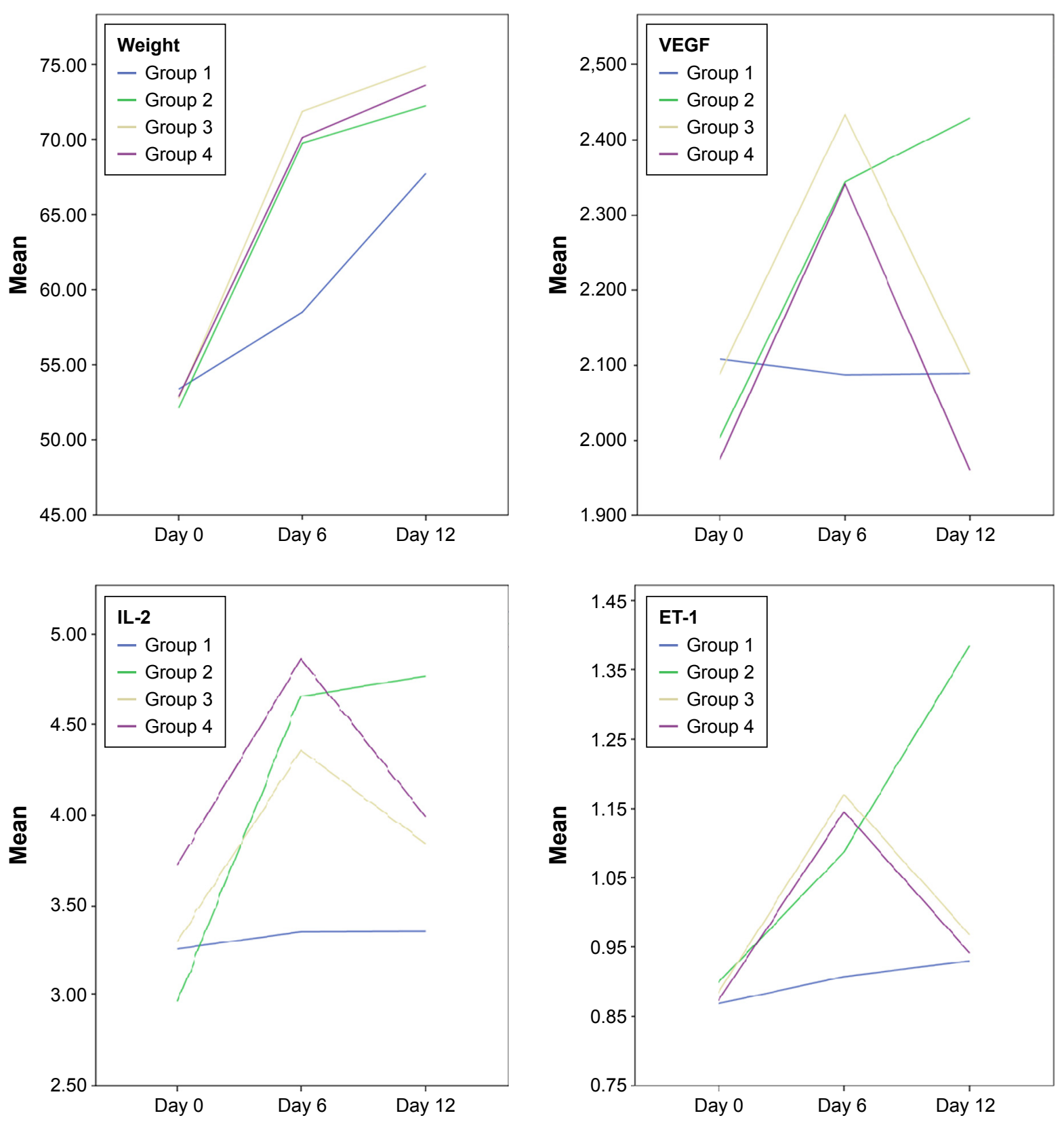

Figure I Weight, serum VEGF, IL-2 and endothelin I tested in the study groups. Day 0: Initially (before the treatment). Day 6: When OHSS was established. Day I2: After the treatment.

Abbreviations: VEGF, vascular endothelial growth factor; ET-I, endothelin-I.

between group 2 and the other groups in terms of ET-1, IL-2, and VEGF values were significant in binary comparisons. According to our results, both treatment modalities (cabergoline and celecoxib) were successful in the treatment of OHSS.

COX-2 has been shown to be a potent angiogenic factor in many systems. ${ }^{17,18}$ A study conducted by Fujii et al demonstrated that, as a result of local production of arachidonic acid metabolites by COX-2, VEGF, which is primarily responsible for vascular permeability, is increased. ${ }^{19} \mathrm{COX}-2$ is stimulated by various factors such as cytokines, growth factors, and tumor promoters. It is also upregulated in many cancers associated with increased VEGF production and angiogenesis. ${ }^{20}$ At the end of treatment, although noteworthy differences were observed between the OHSS group and the celecoxib group, the differences between the control group and celecoxib group were not statistically significant in terms of the evaluated parameters. This finding means that celecoxib was successful in treating OHSS. We believe that this effect is due to inhibition of angiogenesis and VEGF as a result of inhibition of the COX-2 enzyme as emphasized in the studies conducted earlier. 
Table I One-way ANOVA analysis of weight, hematocrit, serum VEGF, IL-2, and ET-I levels of all rats in the study

\begin{tabular}{|c|c|c|c|c|c|}
\hline Parameters & Group I $(n=8)$ & Group $2(n=8)$ & $\begin{array}{l}\text { Group } 3(\mathrm{n}=8) \\
\text { Cabergoline } \\
(100 \mathrm{mg} / \mathrm{kg})\end{array}$ & $\begin{array}{l}\text { Group } 4(\mathrm{n}=8) \\
\text { Celecoxib } \\
(25 \mathrm{mg} / \mathrm{kg})\end{array}$ & $P$-value \\
\hline \multicolumn{6}{|l|}{ Weight (g) } \\
\hline On day 0 & $53.4 \pm 5.8$ & $52.0 \pm 6$ & $52.7 \pm 5.1$ & $52.8 \pm 5.2$ & 0.979 \\
\hline On day 6 & $61.5 \pm 5.6^{\mathrm{a}}$ & $69.8 \pm 2.8^{\mathrm{b}}$ & $71.9 \pm 6.6^{\mathrm{b}}$ & $70.1 \pm 5.2^{b}$ & $0.001 *$ \\
\hline On day 12 & $67.8 \pm 5.8$ & $75.3 \pm 6.3$ & $74.8 \pm 5.4$ & $73.6 \pm 5.4$ & 0.158 \\
\hline \multicolumn{6}{|l|}{ Hematocrit (\%) } \\
\hline On day 0 & $38.6 \pm 1.6$ & $38.2 \pm 1.4$ & $37.6 \pm 1.9$ & $36.6 \pm 2.8$ & 0.817 \\
\hline On day 6 & $39.4 \pm 1.8^{\mathrm{a}}$ & $44 \pm 1.6^{b}$ & $45.4 \pm 1.2^{\mathrm{b}}$ & $45.8 \pm 1.4^{b}$ & $0.004 *$ \\
\hline On day 12 & $40.2 \pm 1.5$ & $42.8 \pm 1.8$ & $40.2 \pm 0.8$ & $39.4 \pm 1.2$ & 0.674 \\
\hline \multicolumn{6}{|l|}{ VEGF (pg/mL) } \\
\hline On day 0 & $2108 \pm 183$ & $2003 \pm 222$ & $2087 \pm 3 \mid 4$ & $1974 \pm 145$ & 0.533 \\
\hline On day 6 & $2087 \pm 134^{a}$ & $2344 \pm 208^{b}$ & $2433 \pm 287^{b}$ & $2341 \pm 137^{b}$ & $0.012^{*}$ \\
\hline On day 12 & $2089 \pm 133^{b}$ & $2428 \pm 217^{a}$ & $2090 \pm 254^{b}$ & $1960 \pm 126^{b}$ & $0.001 *$ \\
\hline \multicolumn{6}{|l|}{ ET-I (ng/mL) } \\
\hline On day 0 & $0.9 \pm 0.1$ & $0.92 \pm 0.1$ & $0.9 \pm 0.2$ & $0.9 \pm 0.2$ & 0.786 \\
\hline On day 6 & $0.9 \pm 0.1^{a}$ & $1.1 \pm 0.2^{b}$ & $1.2 \pm 0.2^{\mathrm{b}}$ & $1.1 \pm 0.2^{b}$ & $0.018^{*}$ \\
\hline On day 12 & $0.9 \pm 0.2^{b}$ & $1.4 \pm 0.2^{\mathrm{a}}$ & $1.0 \pm 0.1^{\mathrm{b}}$ & $0.9 \pm 0.1^{b}$ & $0.002 *$ \\
\hline \multicolumn{6}{|l|}{ IL-2 (pg/mL) } \\
\hline On day 0 & $3.3 \pm 0.6$ & $3.0 \pm 0.6$ & $3.3 \pm 0.7$ & $3.7 \pm 0.5$ & 0.128 \\
\hline On day 6 & $3.4 \pm 0.4^{a}$ & $4.7 \pm 1.3^{b}$ & $4.4 \pm 1.0^{b}$ & $4.9 \pm 1.2^{b}$ & $0.015^{*}$ \\
\hline On day 12 & $3.4 \pm 0.4^{b}$ & $4.8 \pm 1.0^{a}$ & $3.8 \pm 0.4^{b}$ & $4.0 \pm 0.8^{b}$ & $0.038^{*}$ \\
\hline
\end{tabular}

Notes: ANOVA and Tukey's post hoc test were performed. Mean values with different superscripts in rows are significantly different from each other $(P<0.05)$. Group I (control group) received $0.2 \mathrm{~mL}$ of subcutaneous saline for 6 consecutive days (days 25-30) and no further intervention. Group 2 received no intervention after hCG was

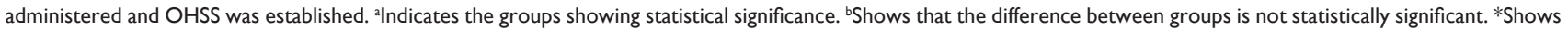
the degree ( $P$-value) of the statistically significant difference.

Abbreviations: VEGF, vascular endothelial growth factor; ET-I, endothelin-I; hCG, human chorionic gonadotropin; OHSS, ovarian hyperstimulation syndrome.

VEGF is an important mediator of OHSS that stimulates angiogenesis in endothelial cells and enhances vascular permeability. ${ }^{21} \mathrm{HCG}$ administration significantly increases VEGF, which leads to increased vascular permeability. ${ }^{7}$ Treatment with either cabergoline alone or in conjunction with a gonadotropin-releasing hormone antagonist was recommended, when appropriate, to reduce the effects of VEGF and subsequently OHSS..$^{22,23}$ The results of our study showed that celecoxib decreased VEGF levels by at least as much as cabergoline (group 4 vs group 3).

ET-1, a powerful vasoconstrictor, may be responsible for increased vascular permeability in many tissues. High levels of ET-1 were detected in patients receiving ovulation induction therapy. ET-1 was found at concentrations 100-300 times higher in follicular fluid samples compared to plasma samples. In addition, there was a positive correlation between ET-1 and FSH, suggesting a potential role for ET-1 in OHSS. ${ }^{24}$ Similar to previous studies, our results demonstrated that after ovulation induction, OHSS rats had higher
ET-1 levels compared to controls. Moreover, treatment with both medications (cabergoline and celecoxib) resulted in reduced ET-1 levels when compared to controls.

Previous studies have reported expression of IL-2 and IL-2 mRNA in cultured luteinized granular cells. As a result of hCG stimulation, granulosa cells may produce an excessive amount of IL-2, leading to vascular leakage syndrome similar to that seen in OHSS. ${ }^{25}$ This study showed that compared to the control group, the OHSS-induced rat groups had significantly higher IL-2 levels. However, after treatment with cabergoline or celecoxib, there was no significant difference when groups 3 and 4 were compared with the control group. However, at the end of treatment, there was a significant difference in IL-2 levels between group 2 (without any treatment after OHSS was established) and the other groups (group 2 vs others groups, $P=0.038$ ).

A study conducted by Quintana et al showed that the incidence of OHSS can be decreased by using meloxicam, a COX-2 inhibitor, in a rat model.${ }^{14}$ However, meloxicam 
is not recommended for in vitro fertilization cycles because it inhibits the release of mature follicles and suppresses ovulation. ${ }^{26}$ Huang et al demonstrated that in hyperstimulated ovaries, electroacupuncture administration, through regulation of COX-2, decreases luteal formation and promotes luteal functional regression. ${ }^{27}$ These studies have shown that prostaglandins play an important role in the pathophysiology of OHSS. The great advantage of using celecoxib in our study is that, unlike other COX-2 inhibitors, its side effects on ovulation are minimal. Some preliminary work showed that the deterioration of OHSS may be accelerated by prostaglandin E2. ${ }^{28,29}$ Therefore, we think that the low level of VEGF, ET-1, and IL-2 is not a coincidence when comparing the control group with the celecoxib group. In this study, for the first time, I provided firm evidence that celecoxib decreases VEGF, IL-2, and ET-1 in OHSS-induced rats. Similarly, Elia et al demonstrated that metformin decreased the release of vasoactive molecules such as VEGF and COX-2 and has a beneficial effect in preventing OHSS. ${ }^{30}$

The first and most important limitation of our study may be its failure to create the exact model that presents symptoms of OHSS similar to those observed in clinical practice. Although we found significant differences in terms of the parameters compared, another limitation of this study was that the correlation with the OHSS grade could not be established. Moreover, the relatively small size of our sample can be considered as another limitation.

\section{Conclusion}

This study distinctly showed that by decreasing VEGF, ET-1, and IL-2 levels, cabergoline and celecoxib could improve the features of OHSS. However, the precise effect of celecoxib on these markers still needs to be investigated. It appears that celecoxib treatment may be a better option for highrisk patients to prevent progression of OHSS. Before being administered in clinical practice, further studies and clinical trials are required to provide reliable results on the effects of celecoxib treatment.

\section{Disclosure}

The author reports no conflicts of interest in this work.

\section{References}

1. Kumar P, Sait SF, Sharma A, Kumar M. Ovarian hyperstimulation syndrome. J Hum Reprod Sci. 2011;4(2):70-75. doi:10.4103/09741208.86080

2. Humaidan P, Quartarolo J, Papanikolaou EG. Preventing ovarian hyperstimulation syndrome: guidance for the clinician. Fertil Steril. 2010;94:389-400. doi:10.1016/j.fertnstert.2010.03.028

3. Naredi N, Talwar P, Sandeep K. VEGF antagonist for the prevention of ovarian hyperstimulation syndrome: current status. Med J Armed Forces India. 2014;70:58-63. doi:10.1016/j.mjafi.2012.03.005
4. Elchalal U, Schenker JG. The pathophysiology of ovarian hyperstimulation syndrome - views and ideas. Hum Reprod. 1997;12:1129-1137.

5. Fraser HM, Duncan WC. SRB Reproduction, Fertility and Development Award Lecture 2008. Regulation and manipulation of angiogenesis in the ovary and endometrium. Reprod Fertil Dev. 2009;21:377-392. doi:10.1071/RD08272

6. Soares SR. Etiology of OHSS and use of dopamine agonists. Fertil Steril. 2012;97:517-522. doi:10.1016/j.fertnstert.2011.12.046

7. Gómez R, Soares SR, Busso C, Garcia-Velasco JA, Simón C, Pellicer A. Physiology and pathology of ovarian hyperstimulation syndrome. Semin Reprod Med. 2010;28:448-457. doi:10.1055/s-0030-1265670

8. Carizza C, Abdelmassih V, Abdelmassih S, et al. Cabergoline reduces the early onset of ovarian hyperstimulation syndrome: a prospective randomized study. Reprod Biomed Online. 2008;17:751-755. doi:10.1016/ S1472-6483(10)60401-4

9. Orvieto R, Dratvinman-Storobinsky O, Lantsberg D, Haas J, Mashiach R, Cohen Y. Interleukin-2 and SOCS-1 proteins involvement in the pathophysiology of severe ovarian hyperstimulation syndrome - a preliminary proof of concept. J Ovarian Res. 2014;7:106. doi:10.1186/s13048-014-0106-2

10. Schenker JG. Clinical aspects of ovarian hyperstimulation syndrome. Eur J Obstet Gynecol Reprod Biol. 1999;85:13-20. doi:10.1016/S03012115(98)00276-0

11. Masferrer J, Leahy KM, Koki AT, et al. Antiangiogenic and antitumor activities of cyclooxygenase-2 inhibitors. Cancer Res. 2000;60(5):1306-1311.

12. Laschke MW, Menger MD. In vitro and in vivo approaches to study angiogenesis in the pathophysiology and therapy of endometriosis. Hum Reprod Update. 2007;13(4):331-342. doi:10.1093/humupd/dmm006

13. Varnagy A, Bodis J, Manfai Z, Wilhelm F, Busznyak C, Koppan M. Low-dose aspirin therapy to prevent ovarian hyperstimulation syndrome. Fertil Steril. 2010;93:2281-2284. doi:10.1016/j.fertnstert.2009.01.085

14. Quintana R, Kopcow L, Marconi G, Young E, Yovanovich C, Paz DE. Inhibition of cyclooxygenase-2 (COX-2) by meloxicam decreases the incidence of ovarian hyperstimulation syndrome in a rat model. Fertil Steril. 2008;90:1511-1516. doi:10.1016/j.fertnstert.2007.09.028

15. Efstathiou JA, Sampson DA, Levine Z, et al. Nonsteroidal antiinflammatory drugs differentially suppress endometriosis in a murine model. Fertil Steril. 2005;83(1):171-181. doi:10.1016/j.fertnstert.2004.06.058

16. Ohba T, Ujioka T, Ishikawa $\mathrm{K}$, Tanaka N, Okamura H. Ovarian hyperstimulation syndrome-model rats; the manifestation and clinical implication. Mol Cell Endocrinol. 2003;28:47-52. doi:10.1016/S03037207(03)00061-3

17. Cianchi F, Cortesini C, Fantappie O, et al. Cyclooxygenase-2 activation mediates the proangiogenic effect of nitric oxide in colorectal cancer. Clin Cancer Res. 2004;10(8):2694-2704. doi:10.1158/1078-0432.CCR-04-1002

18. Wu AW, Gu J, Li ZF, Ji JF, Xu GW. COX-2 expression and tumor angiogenesis in colorectal cancer. World J Gastroenterol. 2004;10(16): 2323-2326. doi:10.3748/wjg.v10.i16.2323

19. Fujii E, Irie K, Ohba KI, et al. Role of nitric oxide, prostaglandins and tyrosine kinase in vascular endothelial growth factor-induced increase in vascular permeability in mouse skin. Naunyn Schmiedebergs Arch Pharmacol. 1997;356(4):475-480. doi:10.1007/PL00005079

20. Toomey DP, Murphy JF, Conlon KC. COX-2, VEGF and tumour angiogenesis. Surgeon. 2009;7(3):174-180. doi:10.1016/S1479666X(09)80042-5

21. Chen SU, Chou CH, Lee H, Ho CH, Lin CW, Yang YS. Lysophosphatidic acid up-regulates expression of interleukin- 8 and -6 in human granulosa-lutein cells through LPA receptors and NF- $\kappa$ B dependent pathways: implications for angiogenesis of corpus luteum and ovarian hyperstimulation syndrome. J Clin Endocrinol Metab. 2008;93:935-943. doi:10.1210/jc.2007-1512

22. Gaafar SS, El-Gezary DA, El Maghraby HA. Early onset of cabergoline therapy for prophylaxis against ovarian hyperstimulation syndrome; a potentially safer and more effective protocol. Fertil Steril. 2014;102: e308. doi:10.1016/j.fertnstert.2014.07.1243

23. Rollene NL, Amols MH, Hudson SBA, Coddington CC. Treatment of ovarian hyperstimulation syndrome using a dopamine agonist and gonadotropin releasing hormone antagonist: a case series. Fertil Steril. 2009;92:1169.e15-1169.e17. doi:10.1016/j.fertnstert.2009.05.062 
24. Schenker JG. Clinical aspects of ovarian hyperstimulation syndrome. Eur J Obstet Gynecol Reprod Biol. 1999;85:13-20. doi:10.1016/S03012115(98)00276-0

25. Orvieto R, Dratviman-Storobinsky O, Cohen Y. Interleukin-2 production by cultured human granulosa cells. Am J Reprod Immunol. 2015; 74:392-397. doi:10.1111/aji.12416

26. Jesam C, Salvatierra AM, Schwartz JL, Croxatto HB. Suppression of follicular rupture with meloxicam, a cyclooxygenase- 2 inhibitor: potential for emergency contraception. Hum Reprod. 2010;25(2):368-373. doi:10.1093/humrep/dep392

27. Huang X, Chen L, Xia YB, Xie M, Sun Q, Yao B. Effects of electroacupuncture on luteal regression and steroidogenesis in ovarian hyperstimulation syndrome model rat. Life Sci. 2018;197:1-9. doi:10.1016/j. lfs.2018.01.026
28. Kowalewski MP, Ihle S, Siemieniuch MJ, et al. Formation of the early canine CL and the role of prostaglandin E2 (PGE2) in regulation of its function: an in vivo approach. Theriogenology. 2015;83:1038-1047. doi:10.1016/j.theriogenology.2014.12.006

29. Galvao A, Skarzynski D, Ferreira-Dias G. Nodal promotes functional luteolysis via down-regulation of progesterone and prostaglandins E2 and promotion of PGF2alpha synthetic pathways in mare corpus luteum. Endocrinology. 2016;157:858-871. doi:10.1210/en.2015-1362

30. Elia EM, Quintana R, Carrere C, et al. Metformin decreases the incidence of ovarian hyperstimulation syndrome: an experimental study. J Ovarian Res. 2013;6(1):62. doi:10.1186/1757-2215-6-62

\section{Publish your work in this journal}

Drug Design, Development and Therapy is an international, peerreviewed open-access journal that spans the spectrum of drug design and development through to clinical applications. Clinical outcomes, patient safety, and programs for the development and effective, safe, and sustained use of medicines are the features of the journal, which has also been accepted for indexing on PubMed Central. The manuscript management system is completely online and includes a very quick and fair peer-review system, which is all easy to use. Visit http://www.dovepress.com/testimonials.php to read real quotes from published authors.

Submit your manuscript here: http://www.dovepress.com/drug-design-development-and-therapy-journal 